\title{
A hipótese do rato: Valor e Medo na LITERATURA AFROBRASILEIRA CONTEMPORÂNEA
}

\author{
The rat: a hypothesis on value and fear in the \\ contemporary afrobrazilian literature
}

\author{
Luiz Maurício Azevedo da Silva ${ }^{1}$ \\ ${ }^{1}$ Universidade de São Paulo. São Paulo, SP, Brasil. \\ E-mail: luizmauricioazevedo@usp.br
}

\section{RESUMO}

O processo de reconfiguração do campo de disputas entre a academia e a autoria negra é o objeto dessa investigação científica que tem como epicentro as tensões políticas entre a literatura produzida por indivíduos negros no século XXI e as condições materiais de sua recepção no Brasil. Trata-se, portanto, de uma hipótese teórica que se proponha a tornar visíveis as engrenagens de produção do valor estético na literatura afrodescendente contemporânea.

PALAVRAS-CHAVE: literatura afro-brasileira; racismo epistemológico; materialismo literário.

EDITOR-CHEFE:

Rachel Esteves Lima

EDITOR EXECUTIVO:

Regina Zilberman

SUBMETIDO: 01.10 .2021

ACEITO: 25.10.2021

\section{COMO CITAR:}

SILVA, Luiz Maurício

Azevedo da. A hipótese

do rato: Valor e medo na

literatura afrobrasileira

contemporânea. Revista

Brasileira de Literatura

Comparada,v.24,n.45,p.87-94,

jan./abr., 2022. doi: https://

doi.org/10.1590/2596-

304x20222445lmas

\section{ABSTRACT}

The making of a reconfiguring process in the field of disputes between academia and the Black authorship is the object of the following paper. This work claims to build a theoretical hypothesis that make visible the gears of production of aesthetic value in contemporary Afro-descendant literature. Hence, one intends to mesure the political tensions between the literature produced by individuals racialized as Black in the 21 st century and the material conditions of its reception in Brazil.

KEYWORDS: african-brazilian literature; epistemic racial prejudice; literary materialism. 
$\mathbf{N}$ as metrópoles não é incomum que a reação humana ao eventual aparecimento de um rato tenha seu desdobramento inteiramente vinculado ao horário do ocorrido. Afinal, é tomado como óbvio o fato de que, seja nos andares profundos da Paulista ou nos subterrâneos das centenas de qualquer cidade com grande densidade demográfica, há ratos por toda parte. O problema ocorre quando decidem - por acidente ou audácia - romper os limites do tácito acordo entre nós e o lixo. Se continuarem lá, em seus buracos e tocas escuras, obedecendo ao ritmo da cidade, é grande a chance que permaneçam vivos. Contudo, se aparecerem durante o dia, no útero do horário comercial, no miolo do ritmo produtivo, proliferam as críticas à prefeitura, à cidade e, por fim, ao nosso modo urbano de viver. Há qualquer coisa de subversivo no ato de aparecer onde não se é chamado. $\mathrm{O}$ mesmo ocorre com os autores e autoras negras. Se essas figuras se dedicarem à autopublicação, aos saraus restritos, às oficinas beneficentes, enfim, ao circuito alternativo já conhecido, receberão o epíteto de produtores e produtoras de literatura negra. Se aparecerem, contudo, à luz do dia, nos lugares destinados ao prestígio literário, estarão pavimentando a estrada de sua danação, exatamente como os roedores das metrópoles que abrigam as livrarias onde diariamente centenas de títulos lutam para chegar à visibilidade dos prêmios literários, dos PNLD's e das resenhas publicitárias publicadas em suplementos e jornais.

Meus exercícios metafóricos outra função não possuem senão a de transformar com palavras e pensamento a realidade que traduzem. A comparação entre autores negros e ratos é ideia minha, mas a formatação dessa correspondência para além das minhas elucubrações linguísticas é do mercado editorial. É ele quem confirma as suspeitas de que os produtores negros de ficção, no capitalismo tardio brasileiro, são vistos percebidos como pragas, a quem a vida biológica deve ser tolerada somente dentro de aspectos bem específicos.

Muito já se disse sobre o racismo e suas mais variadas manifestações na cultura brasileira. Também se explorou ad nauseam a necessidade de um sistema literário que respondesse mais adequadamente às demandas sociais e que representasse nossa diversidade étnica. Nessa legítima guerra, entretanto, restou vilipendiada a extensão do impacto dessa renovação estética no campo literário nacional. É certo que muito pouco mudou no que diz respeito às estruturas que sustentam nossa cultura doméstica, mas é igualmente verdadeiro que a mínima transformação na aparência das coisas já gerou uma espécie de clima de opinião segundo o qual o sistema literário brasileiro estaria em franca erosão. Esse sentimento, misturado ao já tradicional fetichismo da vida negra, gerou uma crença de que a experiência afrodiaspórica poderia significar uma oportunidade de correção da história da civilização, uma espécie de segunda chance da cultura. Os indivíduos negros teriam direito a seu próprio modernismo e a seu próprio pós-modernismo; e poderiam gozar daquilo que, na literatura tout-court, já se encontrava roto. Ao contrário dos eurodescendentes, eles poderiam simplesmente começar na parte que interessava, criar seus mitos a partir da centralidade de décadas mais interessantes, deixando de lado os fracassos do Classicismo, do Arcadismo e do Romantismo.

Assim, uma cultura literária negra teria, ainda segundo esse olhar, a vantagem de começar sua historiografia já no Realismo, tendo em Memórias póstumas de Brás Cubas - e não na pitoresca carta de Pero Vaz de Caminha - sua real certidão de nascimento. Adicione-se à equação desastrosa a 
presunção de que a cultura negra não precisaria lidar com as grandes disputas ideológicas do campo artístico até aqui, porque afinal negros não são nem trotskistas nem stalinistas; nem formalistas, nem estruturalistas; nem liberais nem materialistas. Eram - e continuam sendo - figuras às quais se deve apresentar o marxismo, o feminismo, a psicanálise, as pirâmides transparentes do Louvre e o que mais for óbvio, para que um dia, a partir dessa catequização bem-intencionada, com as ferramentas certas, eles próprios consertem o que há de errado no mundo.

Muitos autores não-negros e muitas autoras não-negras, a despeito de suas inteligências e de suas afinidades afetivas, sentiram-se seduzidos e seduzidas por essa fantasia ${ }^{1}$. Parece existir uma pulsão de cobiça, de natureza narcisística desejosa, através da qual o próprio desejo de prestígio encontra receptáculo na presunção de que literatos negros e literatas negras gozam de expedientes críticos diferenciados. A crítica literária estaria sufocada por pressões antropológicas. E, para se livrar delas, o único dispositivo disponível seria a emulação de uma espécie de negritude difusa, representada no resgate de uma suposta ancestralidade africana comum a todo povo brasileiro. $O$ que antes atendia pelo nome de mito da democracia racial passa agora a responder pelo que é, a dimensão literária de uma fantasia ${ }^{2}$. Quanto mais visíveis se tornaram os elementos que sustentavam o conto da igualdade racial brasileira, mais importante se tornou representar exploração de negros por brancos nos livros, nos filmes e em toda representação artística disponível. A arte passou a ser não mais o campo da denúncia, mas do regozijo, o único local onde o sadismo do opressor pode desfilar fazendo as vezes de memória renitente do oprimido.

Não se trata mais de fazer uma "literatura de brancos", mas uma literatura que possa receber o espólio de guerra expropriado das comunidades negras. Nesse sentido, a reivindicação de autoria negra não passa mais pela politização do texto, mas pela consciência dos lucros e dividendos que essa identidade pode ofertar aos autores que a ela forem atribuídos. Evidentemente, não se trata mais de se perguntar se existe literatura negra, mas sim de tomar para si um novo rótulo, o título de negroautor. Todos observam a possibilidade de teatralização da vida social étnica, dimensão que antes era oferecida apenas às minorias, mas que hoje, dada a profusão de rótulos minoritários, pode ser facilmente reivindicada por aqueles que assim desejarem. O sistema já não procura interditar os sentimentos de inadequação e desajuste, mas de reafirmá-los como forma de afastar o pior dos riscos, o de que o indivíduo perceba, finalmente, que ele importa pouco enquanto ente único. Enquanto procura se equilibrar entre identidades novas, identidades velhas, identidades postiças e identidades precárias, sem saber ao certo de qual delas sairá o passaporte para o prestígio literário, o autor não-negro observa o rato livre, na parte de cima do solo, que se movimenta com a certeza de que não há outros ratos tão espertos quanto eles. Nem tão habilidosos. O rato observa a sua própria vida e se regozija de seus feitos.

\footnotetext{
1 Sobre o tema, vale conferir Corra, de Jordan Peele, filme de 2017, no qual o protagonista negro, em uma viagem para conhecer os pais de sua namorada eurodescendente, se depara com uma família disposta a cometer crimes para se tornar, a qualquer custo, também negra. Trata-se de uma versão tétrica e bem mais interessante de Adivinha quem vem para o jantar, de 1967.

2 Tenho uma particular queda por esse fragmento adorniano: “(...) Existe um amor intellectualis pelo pessoal da cozinha, a tentação para quem faz trabalho teórico ou artístico de afrouxar a exigência intelectual e rebaixar o nível, seguindo na coisa e na expressão todo tipo de hábitos que, como conhecedor alerta, havia rejeitado. Como os intelectuais não podem mais reivindicar para si qualquer categoria dada, nem mesmo a formação cultural, e mil demandas da operosidade ameaçam a concentração, cresce de tal modo o esforço para produzir algo que de algum modo se sustente que quase ninguém consegue levá-lo a cabo. Além disso, a pressão do conformismo, que pesa sobre todo produtor, deprime por si mesma sua autoexigência." (ADORNO, 2018, p. 25). Penso que no Brasil, podemos deslocar o sentido de "pessoal da cozinha" por uma acepção tipicamente brasileira de indivíduo do povo e, nesse caso, negro.
} 
Nunca nenhum roedor chegou tão longe quanto ele. E começa a parecer interessante garantir que no futuro nunca ninguém o faça. Então, as eventuais armadilhas que encontra no caminho, e que pode desarmá-las para que não firam outros ratos são ardilosamente deixadas intactas. Em seu movimento, todas as alterações de rota parecem planejadas pela urgência dos cheiros, das novidades, dos prazeres. Tudo é justificado. Nunca se esteve ali, afinal. Enquanto isso, uma legião de ratos dorme sob a cidade. De qualquer forma, o autor não-negro, ainda que enojado, não vê opção além de assistir ao espetáculo do domínio dos outros, das escolhas do outro, dos movimentos do outro. Enquanto o rato estiver na parte de cima, a avenida é dele. E parece, para todos aqueles que não são ratos, que a avenida nunca voltará a ser domínio dos humanos, porque é isso afinal o que se pensa no coração de uma crise. Pensase que a crise é infinita, porque as crises cancelam as possibilidades de juntar o ontem ao amanhã. A crise é a destruição da face futuro do deus Jano. Nela, só se pode ver o antes.

\section{O ARRAZOADO DOS ROEDORES}

Que os filhos da burguesia, já empanturrados de tanto sabor, croissant e Moët Chandon, tenham migrado lentamente do sonho de mudar o mundo para a realidade paquidérmica de terem sido mudados por ele, não é exatamente algo surpreendente; que hoje diversos bancos procurem diluir uma parte mínima de seus lucros em projetos culturais, convertendo prédios em instalações - em certos casos ocupações - artísticas, também não é novo; que exista sempre uma parte do proletariado disposta a fornecer aos patrões motivos para continuarem afrouxando os arreios que os prendem, ainda que isso custe o adiamento da libertação dos outros, isso também já é matéria revisada. O que há de realmente novo nessa terceira década do século XXI é o fato de as minorias terem preferido o discurso emulado do cansaço, da perda das utopias, e que tenham elas mesmas preferido fingir experimentar um empanturramento de tentativas de lutas contra o capital e que o melhor a fazer agora seria dizer um não peremptório a qualquer projeto intelectual que suponha revide.

Trata-se de um aspecto particular do período econômico que a maior parte de meus pares gosta de chamar de neoliberalismo, mas que para mim não é outra coisa senão o capitalismo de comutação. Chamo assim porque muito além de um conjunto de doutrinas econômicas e de diretrizes políticas, o capitalismo atual possui uma cartilha de intenções publicizadas onde nada mais há de escondido. Assim, grande parte da crítica que a ideologia marxista encontrava como necessária - o esclarecimento das massas, a catequização política do oprimido - foi sendo identificado como estupidez do narrador. Tal qual um aluno que toma o professor por obtuso por confundir seu didatismo generoso com limitação argumentativa. A mediação como linguagem desaparece do horizonte de expectativas. Daí advém o jorro de repercussões generalizadas, anti-intelectuais e imprecisas: toda psicanálise é um desejo de falar sobre algo para não ter que encará-lo; toda diplomacia é a argumentação da falta de condições para o uso da força; toda crítica literária não passa de um entrave à consagração dos autores.

A razão dos ratos, nesse caso, residiria na confrontação inevitável dos elementos que se apresentam como imutáveis, dos quais o capitalismo de comutação se alimenta. O rato sabe que não é o centro do processo explorador. Ele sabe que há engrenagens. Ele sabe que há valores e cordas que o coordenam. Ele sabe que há o capital. Entretanto, ele acredita ser contraproducente fazer outra coisa senão o que faz, afinal, uma engrenagem só pode funcionar para o lado certo ou parar de funcionar, à espera da óbvia 
substituição. Confrontar-se com o capital é, para ele, adiar o desejo profundo que é aproximar-se do capital. O engajamento não apenas não faz mais sentido porque ele não odeia o patrão; ele agora odeia ser empregado. É por isso que, como autor, o rato sente-se representante não mais de seus semelhantes roedores, mas do sistema que o levou à superfície.

\title{
UMA OXIGENAÇÃO CONTRA-ARGUMENTATIVA
}

A essa altura, suspeito que a aceitação de um modelo no qual se possa ser representar autores como ratos e cena pública como avenidas já esteja relativamente mais assentada. Restaria avançar para uma ideia de potência dialético-transformativa dessa realidade, mas antes é preciso enfrentar o problema da industrialização do comportamento de autor:

\begin{abstract}
Os críticos literários podem pensar que os indivíduos são incomparáveis, mas os sociólogos discordam. Se os seres humanos fossem, na maioria, encantadoramente imprevisíveis, os sociólogos perderiam o emprego. Eles, como os stalinistas, não se interessam pelo indivíduo. Pelo contrário, examinam padrões comuns de comportamento. É uma verdade sociológica que as filas nas caixas de supermercado sempre são mais ou menos do mesmo comprimento, pois os seres humanos são semelhantes em sua relutância de perder tempo demais com tarefas tediosas e relativamente triviais, como pagar as compras no mercado. Seria realmente estranho que alguém fizesse fila só para se divertir. Nesse caso, seria uma boa ação avisar os serviços de assistência social. (EAGLETON, 2019, p. 60).
\end{abstract}

A maioria de nós rejeita, por ofício, a equiparação de agentes da literatura à dimensão robotizada de players de mercado. Habita ainda por aí um forte senso de que, subtraídas as tensões mercantis, os autores são, afinal, seres humanos capazes de responder com liberdade e assertividade aos desafios propostos por seu próprio campo de atuação. Concordaria com isso, se isso fosse verdade. Contudo, isso pressupõe que os autores nasçam por si próprios, através de um processo de geração espontânea, sem qualquer relação com as condições materiais que o cercam. Considerando o modo como as coisas se processam no mundo cultural, é razoável concluir que autores não apenas reagem às coisas à medida que elas se apresentam, mas que também alteram, com seu comportamento, suas feições. Assim, retornando à metáfora que dá origem a esse artigo, o ato de andar pela avenida livre, o ato de ser visto, de exercer o que parece ser liberdade, altera o cenário no qual o rato transita, de maneira que, conforme vai avançando em suas vontades, confirma que só pode exercer a regência plena por meio de um cancelamento não do outro, porque esse é necessário para que se testemunhem o seu valor, mas da capacidade de ação desse outro. Passa a ser essencial para o rato trabalhar para a aniquilação das possibilidades de agência de quem o assiste viver. Nesse sentido, o autor negro começa a trabalhar contra a audiência que antes desejava adular. Esse trabalho, no entanto, leva tempo para se tornar visível. Dele primeiro vemos apenas elementos indiciários, que apontam para um incômodo. $\mathrm{O}$ desejo do rato é controlar a interação dos outros, mas o que consegue, por acidente, é perturbá-los. Essa perturbação pode - e deve - ser captada pela crítica literária como único elemento vivo e orgânico de uma relação artística já agonizante. É nesse sentido, aliás, que argumenta Durão: 
O trabalho crítico de gerações futuras mostra inequivocamente o quanto a grande obra continha os germes das décadas ou mesmo dos séculos vindouros. Na verdade, isso é uma condição para que determinado texto possa surgir como grande obra. O passado de um objeto literário de peso confundese com seu valor no presente; quando não há mais nada a dizer a seu respeito, ele se converte em mero documento histórico. (DURÃO, 2016, p. 27).

É razoável afirmar, portanto, que há uma potência criativa mesmo nesses cenários em que as tensões cotidianas apontam para uma suposta estagnação e convidam para um repouso da força crítica. $\mathrm{O}$ que de pior as obras apresentam hoje pode ser, no futuro, os principais confirmadores de sua importância. Assim, em uma realidade cultural na qual as obras produzidas por autores negros não desejam outra coisa senão a aceitação de que são obras, aquilo que em primeiro lugar se apresentaria como a evidência de uma profunda ingenuidade artística passa a ser a semente única de uma pulsão já inexistente nos demais lugares ${ }^{3}$.

Nesse sentido, ainda que autores negros e mercado editorial tenham se concentrado na possibilidade real de que a literatura valha somente como conteúdo paradidático, essa decisão não tem validade futura, pois tanto mercado quanto autores negros não podem desenhar seus próprios desdobramentos, uma vez que precisam gastar todas as suas energias na afirmação do presente ${ }^{4}$. Grosso modo, estão ambos interessados em resguardar um certo elemento iluminista de que a literatura é fundamental na formação do ser humano, e, portanto, não apenas direito, mas um elemento luxuoso em uma educação sofisticada. Para além dos conteúdos básicos, o instrumento literário seria um acessório a mais em um conjunto de gadgets da educação contemporânea, algo a ser levado em conta na hora da escolha da escola das crianças, um asterisco em um panfleto educacional publicitário. Essa operação instrumentaliza suas obras, mas também as libera da defesa sempre inútil do espetáculo - inútil no capitalismo tardio - do direito à inutilidade da arte ${ }^{5}$. Já de saída essa literatura negra se reivindica como necessária e, portanto, portadora de uma mensagem cujo alcance se limitaria ao campo dos estudos escolares, território no qual a literatura, para existir, deve estar impregnada de um sentido cultural, mas inofensivo.

3 Atualmente, a produção literária de um indivíduo negro pode parecer - aos olhos dos desatentos - uma grande oportunidade para assistirmos ao triunfo do indivíduo sobre o social. Contudo, o fato de que os acertos estéticos de autores negros tenham permanecido sem reverberação comercial adequada por tantas décadas oblitera a fantasia de que nosso sistema literário seja outra coisa senão uma máquina de explicações palatáveis e domesticadoras sobre como - e principalmente por que - chegamos ao inferno que hoje habitamos. As narrativas que porventura escapam desse modelo produtivo são vilipendiadas e rotuladas como indignas de nota, e passam a habitar um limbo do qual raramente são retiradas.

4 "Cada vez que escrevo um artigo ou um ensaio, pareço estar certo de que a arte diminui a velocidade das ações sociais e assim permite que observemos as engrenagens através das quais a realidade objetiva se sustenta. A obra de ficção seria uma peça que tem como moldura as condições de vida que a geraram. Entretanto, essa sensação dura somente alguns minutos. Logo sou lançado novamente ao vazio de uma suspeita assustadora: a de que a arte, a verdadeira arte, é somente um artifício para nos distrair da realidade. Não seria, então, o blockbuster tacanho aquilo que nos anestesia, e sim as produções de alta cultura das quais tanto gostamos. O que não suportamos em programas dominicais da TV aberta brasileira não é, talvez, sua inacreditável irrealidade, mas sua incrível capacidade de retratar sem filtros o mundo que aí está: rasteiro, grotesco e desinteressante." (AZEVEDO, 2018, p. 16).

5 A crítica literária é coautora do apagamento de toda uma historicidade intelectual negro-brasileira. Penso especialmente em Sílvio Romero, José Veríssimo, Alceu Amoroso Lima, José Guilherme Merquior, Afrânio Coutinho, Alfredo Bosi, Wilson Martins, Roberto Schwarz, e mesmo em Antonio Candido... nenhum afrodescendente. Há um eloquente vazio da presença negra. O grupo da crítica merecia um outro tipo de metáfora que caracterizasse sua aparência fenotípica homogêneo, masculina e eurodescendente. Se esse artigo se trata das figuras femininas na literatura brasileira, considerando o olhar de nossa tradição crítica, ele teria notas de rodapé ainda menores. 


\section{CONSIDERAÇÕES FINAIS}

Assim como a crise de mão de obra levou ao tráfico negreiro, a crise do sistema editorial brasileiro levou as editoras à neurótica busca pela produção literária negra ${ }^{6}$. De um lado o imperativo de sobrevivência (a base de leitores não é mais o problema, o problema agora é que parecem ter aumentado também as expectativas de leitura). Não basta a uma parcela significativa de novos leitores que Jorge Amado tenha tematizado a vida cultural negra ou que Harriet Beecher Stowe tenha denunciado os horrores da escravidão. A demanda passa a ser não de um novo projeto social - horizonte involuntariamente destruído pelos resmungos da queda do muro de Berlim - e o nascimento de uma visão torta de liberalismo negro, através da qual a ascensão individual não apenas é uma etapa aceitável para a emancipação de toda a comunidade negra, como a única possível. A lógica é aritmética: a revolução das condições coletivas é resultado da soma de superações individuais. Assim, a pauperização dos indivíduos negros será extinta mediante o enriquecimento sucessivo de indivíduos negros. Do mesmo modo, a visibilização da literatura negra será alcançada mediante a visibilização dos autores. Nenhum compromisso coletivo é estabelecido porque o individualismo veste hoje as roupas da individualidade. Restará, portanto, uma única saída, de ordem crítica $^{7}$ : a de ruptura completa com a presunção de que autores negros fazem parte de um conjunto de pragas inevitáveis do mundo urbano. É preciso trabalhar para que não percam essa camuflagem que os protege e que permite que circulem sob o manto da manutenção da vida biológica, mas é necessário fomentar um pensamento que não espere dos objetos a confirmação de potências que dependem da crítica, afinal, um rato - tenha ele a cor que tiver - não pode identificar se está ao lado de uma barra de ouro ou do transformador eletrificado que lhe retirará a vida.

6 Não há dúvidas de que a promulgação da Lei 10639, que estabelece a obrigatoriedade do ensino de história e cultura afrobrasileiras, teve grande impacto nesse cenário. Ademais, a realidade escolar tende a, quando exposta ao calor urgente das demandas concretas, sugerir a substituição de apuro estético por instrumentalidade pedagógica. Nesses casos, o tema passa a valer mais do que as obras.

7 Debate semelhante foi proposto por Clovis Moura, na década de oitenta, em relação à necessidade de se resgatar a força crítica da sociologia. Dizia ele: "A sociologia acadêmica nada mais é do que um ramo de conhecimento e atividade criado no transcurso da elaboração de uma ideologia racionalizadora, capaz de suprir a necessidade de se apresentar a sociedade capitalista como eterna e racional. Racional por eterna e eterna por racional." (MOURA, 2021, p. 10). Hoje, entretanto, cada vez que nos estabelecemos, com coragem, na posição de enfrentamento de grandes questões críticas, logo se levantam as vozes que recomendam cautela. Os contínuos ataques à academia e à intelectualidade partem dos mais variados lugares. E, de certa forma, dificultam a modulação de uma crítica consistente que não represente apenas mais um modo de destruir integralmente aquilo que era problemático em parte. De toda sorte, a aplicabilidade da sociologia constitui um valor para as empresas e para o Estado, enquanto a literatura parece interessar somente quando encarnada na mercadoria livro ou como promessa de novos modos de enganar as minorias em silêncio. 


\section{REFERÊNCIAS}

ADORNO, Theodor. Minima Moralia. Rio de Janeiro: Azougue, 2018.

AZEVEDO, Luiz Mauricio. A toupeira invisível: marxismo negro e cultura antimarxista em Ralph Ellison. Porto Alegre: Figura de Linguagem, 2018.

DURÃO, Fabio. O que é crítica literária. São Paulo: Parábola, 2016.

EAGLETON, Terry. Como ler literatura. Porto Alegre: LP\&M, 2019.

MOURA. Clovis. A sociologia posta em questão. Porto Alegre: Figura de Linguagem, 2021. 